\title{
Analysis on the Reflection of Poetic Imagery Beauty of Chinese Gardens in Modern Landscape Design
}

\author{
Xiang Liu \\ Zhengzhou Tourism College \\ Henan, China, 450000
}

\begin{abstract}
With the rapid development of China's modern landscape design, high-speed growth of China's economy as well as the accelerating process of urbanization, people have become more eager to improve the living environment, which makes the landscape design an essential part of modern design. Since China's economy and culture are increasingly integrated with the world, Chinese people have recognized the importance of traditional culture under impact of today's diverse cultures, and their focus on the aesthetic appreciation and design of modern landscape has gradually shifted from the Western landscape system to the landscape design reflecting traditional culture connotation. Therefore, the traditional Chinese garden making techniques have been gradually accepted by the public, also awakening and national pride and self confidence in memory. The Chinese traditional techniques have been tentatively used in the design of a large number of modern landscape architectures. Even with different final effects, it's an attempt to follow the Chinese traditional gardening style with poetic imagery beauty after all. In this paper, the analysis has been conducted from three aspects including the connotation and definition of landscape, the cultural connotation of poetic imagery of Chinese gardens and the specific application of poetic imagery beauty in landscape, thereby presenting some feasible methods for how to integrate Chinese traditional poetic imagery beauty sympathetically into modern landscape design and to create the sense of beauty.
\end{abstract}

Keywords-Chinese gardens; poetic imagery beauty; modern landscape design

\section{INTRODUCTION}

The development and continuation of urban culture require the supports of multiple carriers, while the landscape design is exactly a crucial element in urban culture construction. Landscape is a public space for people to get relaxed and entertained, a space to provide exchanges of culture, information and feelings. With the development of economy, people feel crowded in the city and they need a leisure space to nurture spirituality, relax the mind and enjoy the wonder of natural life after the busy work. Meanwhile, the enjoyment of culture or poetic imagery brought by the landscape design enables people to gain greatly the spirit of joy and sublimation.

Although the origin of garden landscape is relating to the theory "that man is an integral part of nature" which was advocated in China since ancient times, the concept of landscape design comes from the West. As China was economically quite backward in the past over 100 years, the once-booming Chinese gardening art lost its survival soil. Not to mention integrating the poetic imagery beauty of Chinese gardens into the landscape design, there was only few expressions of Chinese elements in the landscape and moreover, most of the landscape design in China after the reform and opening-up was just copying the Western landscape design system, blindly pursuing luxury top-grade material and abundantly using the symmetric form of artificial landscape. Thus, modern designers in China are appealing to landscape design to absorb nutrition from traditional culture and find inspiration. Afterwards, a number of landscape design themed by traditional culture has emerged, which makes the landscape show the diversified development situation. And the Chinese traditional gardening technique has taken its place in the landscape design.

\section{CONnOtATION AND DEFINITION OF LANDSCAPE}

It's said that the term 'landscape' is originated from Hebrew Bible . The Old Testament used to describe the beautiful scenery of the church, castle and palace of the Kingdom of Salomon in Jerusalem. There are different explanations for the term in different fields. In physics, earth science and other subject area, the landscape refers to the comprehensive visual natural phenomenon within the large-area land area on crustal surface. In realm of art, it refers to the photography, painting and other artistic forms describing nature scenery. In the study of bioscience, it refers to an activity which is to improve the natural features of earth surface by creating contour features and planting trees.

In the Dictionary of Chinese Garden Art, the landscape is interpreted as the scene what people perceive about all sorts of natural and artificial sceneries, generally including natural landscape and human landscape. It can be seen from the interpretation that people's perception is subjective condition while scenery is objective condition. Scenery refers to the substance, image or object to be viewed and seeing is the perception process and reception activity of viewers; sightseeing is a result of the interaction between subjects and objects. Specifically speaking, landscape design refers to the creation of a concrete form in a certain area and landscape is a relatively independent scenery composed of form factors with certain cultural connotation and aesthetic value. The term 'landscape' officially emerged in China in1980s and was mainly used as a geographical term at that time. Nowadays, this word has transcended the boundary of landscape painting and become part of the visual aesthetics in real life. 


\section{Cultural CONNOTATion OF POetic IMAGery of Chinese} TRADITIONAL GARDENS

Chinese traditional gardens have provided a man-made and natural combined environment where people can walk, go sightseeing and live. "Scenery" is the soul and life of the garden while the soul of "scenery" is the landscaping elements, such as building, plant, hill stone, water, etc., which convey the unique concept of Chinese culture with their peculiar form.

\section{A. Poetic imagery beauty reflected by the natural theory that "man is an integral part of nature"}

Chinese traditional gardening technique is derived from nature but higher than nature, which is designed to, by subtly combining natural beauty with artificial beauty, achieve the artistic state of "even made by man, but seemingly created by God". In the process of garden art construction, poetic imagery as well as aesthetic culture psychology can never be separated from the theory that "man is an integral part of nature" with Chinese characteristics which is the ideological origin of ecology, philosophy and aesthetics. In Chinese traditional landscape art, taking the theory that "man is an integral part of nature" as aesthetic ideal is to pursue the mutual harmony between natural environment and human living environment and the combination of human spirit and universe nature spirit, making people comprehend unlimited free universe spirit from limited garden landscape environment and finally obtain the liberation of mind through the harmony between man and nature.

The theory that "man is an integral part of nature" has been bestowed with rich connotations in its development history. As aesthetic ideal of Chinese classical garden art, the theory that "man is an integral part of nature" is reflected in the poetic imagery of gardens at multiple levels, not only in gardening purpose and gardening ideology but also in the style of poetic imagery of gardens. Under the guide of the philosophical thought that "man is an integral part of nature", the development of Chinese gardens has been always following the gardening concept "derived from nature but higher than nature", with landscape architecture stressing the permeability and flexibility of space and organically combing with hill stone, water, plant, flower and grass into a unity full of natural charm. The orogenic stone arrangement is better to be based on nature, by abstract and typical wincing, imitating and sketching, to make the natural innumerable mountains and valleys reappear in limited space. The waterscape in gardens roughly simulates the nature water, with natural meandering shore pattern, demonstrating the symbolic meaning "just from a spoon of water to see the running wild rivers" in the limited garden space. The plant is originally an important element richest in natural vitality in the garden. In Chinese classical gardens, what plant cultivation abstains from most is the artificial modification and natural growth is absolutely required, with great attention paid to the demonstration of abundant forms of natural communities by limited flowers and plants. In a word, Chinese classical gardens pursue the beauty of nature, by integrating mountain, water, building, flower and tree into nature, to create a generalized and typical poetic imagery of garden with natural quality, thereby enabling viewers to stay away from the world, return to nature and enjoy the pure beauty of universe with a relaxed mind.

\section{B. Connotation of poetic imagery beauty of Chinese classical gardens}

The phrase 'poetic imagery' can be traced back to the Buddhist texts. Relatively speaking, Buddhists devote most particular care to the poetic imagery. The highest realm of Buddhism is comprehended by human wisdom. On another level, realm and poetic imagery have the same meaning. Numerous discussions about the relationship between 'poetic' and 'imagery' had been held in history. There are "landscape" and "image" in literary creation and criticism. Some lay particular stress on 'poetic' and some regard both 'poetic' and 'imagery' as equally important. However, literally speaking, 'poetic' refers to the thoughts and feelings, belonging to people's subjective consciousness; while 'imagery' refers to scenery which exists objectively. Therefore, 'poetic imagery' is the community of subject and object.

As an important category of Chinese traditional aesthetics, poetic imagery is an artistic state produced after the fusion and collision of feelings and scenes, which displays an aesthetic consciousness and is an interest perceived in aesthetic practice. The poetic elegance and imagery profundity are most significant characteristics of China classical gardens, as said in the verse "Deep, deep the courtyard where he is, so deep" which has described the poet's feeling and pursuit for poetic imagery from the heart. Seriously restricted by historical conditions of feudal society, most of the Chinese classical gardens are closed, namely, the perimeter of the gardens is provided with bounding wall, the scenery is hidden inside the yard and except a few royal palatial gardens, all have relatively small area. Hence, to create diversified, delicate and unique scenery as well as profound and rich poetic imagery, the garden landscape must break through the space limitation and present unlimited garden sceneries in limited space. The landscape layer variety can be enriched and profoundness of scenery can be greatly strengthened by making good use of spatial segmentation and association. The garden constructed by taking advantage of spatial segmentation is able to present the diversification of subject in garden space, with inside garden area divided into several unequal-sized scenic spots each of which has the principal part that may be the rare stone, or famous flower, or mountain and river, or tall bamboo, or dead wood, forming various landscapes of main body; however, the scenic spots are separated but not enclosed: it's accessible between all spots which seems to be separated while still connected, faintly visible, creating rich layering and profound state.

\section{THE REFLECTION OF POETIC IMAGERY BEAUTY IN MODERN LANDSCAPE DESIGN}

\section{A. Poetic imagery beauty of gardens nurtured by aesthetic thoughts of traditional literati}

Gardens are the beautiful ideal of human life, which can nurture our spirituality and mould our sentiments. The beauty 
of Chinese traditional gardens lies in the overall poetic imagery beauty reflected by gardens. Chinese gardens are works of ancient writers, and the poetic imagery beauty can reflect writers' thoughts and sentiments. Besides, the poetic imagery beauty of gardens and landscape has a close connection with the philosophic thoughts and aesthetic thoughts of literati. Therefore, we can utilize these aesthetic thoughts to nurture the poetic imagery beauty of modern landscape design under the new situation.

The impact of Taoist philosophic thoughts is the foundation of Chinese traditional aesthetic thoughts. The Taoism stresses that beauty exists in the relationship between human and nature, pays attention to the harmony between human and nature, and emphasis on the natural, simple and plain beauty. Besides, inaction is a kind of simple beauty. Chuang Tzu even had the spirit integrated into natural landscape, in a sense making nature get liberation. His thoughts' essence is, in the process of construction of gardens, to meet the nature, to go with the flow, and to conform to natural laws. Also, he believes that only "Unity of Man and Nature" is the beauty of natural landscape in the true sense.

In the modern landscape design, we should inherit and carry forward our aesthetic thoughts of Chinese traditional culture, and integrate the thought of natural inaction into the landscape design, thus to show the realization of the ideal in the nature, to be endowed with the simple and natural poetic imagery beauty of gardens, and to make creative themes of modern landscape also have the reflection of the Chinese aesthetics, therefore nurturing the plain poetic imagery beauty.

\section{$B$. The poetic beauty of fiction or fact and light or shadow}

The fiction is intangible, which is vague and cannot be seen; the fact is existent and tangible. In the garden, the garden area size is real and can't be changed, but the space can be illusorily changed. From the analysis of artistic conception of Chinese traditional gardens, the application of fiction or fact are reflected in many relationships, such as sparse and dense, explicit and concealed, light and shadow, etc. From some point of view, this relationship is the relationship of faction and fact, for something dense, explicit and concrete is real, instead something empty, concealed, and foiled is virtual. Thus the fiction and fact is actually complementary to each other, and is reflected by mutual contrast.

In the modern landscape design, making good use of the relationship between fiction and fact can perfectly reflect the poetic imagery beauty of the garden. For example, we can construct the real mountain in the landscape design, which can reflect the beauty of the momentum, and the water we designed should be virtual, which can show the beauty feminineness. In fact, the mountain and water are contrasted, thus to form the relationship of fiction and fact. However, the relationship of fiction and fact of buildings can be shown by the enclosure, for example, open-space corridors and pavilions is virtual space, and the internal space of buildings is real space, and the windows on the wall also are defined to be virtual space. In the modern garden landscape design, we can use ornamental perforated window, which is a part between fiction and fact. The ornamental perforated window is virtual, but the borrowed scene is real, so this kind of relationship between fiction and fact can not only broaden the viewing angle, and extend the garden space, but also greatly enhance the poetic imagery beauty of the landscape.

\section{The poetic imagery beauty of Chinese traditional painting and calligraphy}

The most important feature of Chinese painting is freehand brushwork in traditional Chinese painting. Chinese painting is created through the symbol and freehand brushwork to express the author's understanding of life and feelings, and it uses limited words to convey infinite affection. The poetic imagery beauty of Chinese painting is the sense of heart that the painters want to express with pen and ink, the emotion and ideal of natural landscape flowers and birds, and is the harmony between reality and ideal. How to deal with the problem of art and reality, and the problem of reality and ideal is the core issue of painting aesthetics. Mountains, water, plants and animals in nature are the painting subjects, and most of them adopt the freehand brushwork technique to express feelings, such as plum, orchid, bamboo, chrysanthemum, and so on. These not only provide materials for our modern landscape design on the choice of plants and arrangement, but also integrate the implied meaning and spirit of these plants into the landscape.

Chinese painting is the perfect combination of poetry, calligraphy, paintings, and seal. The poetic imagery beauty of Chinese calligraphy may also have many ties with the performance of the poetic imagery beauty of Chinese gardens, for example, inscriptions, written poems, plaques, and couplets are inseparable from the performance of the writing chirography. Calligraphy and painting are homologous. Although the painting is different from the expression form and content of words, they have one thing in common: the law of formal beauty. Scholars have a passion for calligraphy, and calligraphy's layout, black and white, right and wrong, spare and dense, fiction and fact and other relationships, reflect the rhythm relationship which is the same with the nature of painting. Painting pays attention to the reflection of the artistic conception, while calligraphy also stresses the beauty of artistic conception. The model of Chinese characters is originally pictographic knowing, and the source of the graphics is all things of the nature. The meaning is attached to form, and this meaning has been a part of the artistic conception. In the literati's aesthetics, artistic conception is a prerequisite, so poetry, painting, and even writing should also have feeling and setting happily blended. Beautiful calligraphy is just like a beautiful painting, and beautiful poem is full of life due to the feelings that artists poured into. If elements of painting calligraphy are integrated into the modern landscape design, the landscape will naturally produce beautiful artistic conception beauty.

\section{CONCLUSION}

Chinese traditional landscape stresses Taoist thought of "Unity of Man and Nature" and Chinese ancient scholars' expressing feelings into the nature in order to show their 
moral sentiment. The poetic imagery beauty of landscape is the overall beauty of the garden which is shown in the poetic imagery beauty conveyed by the gardening elements, and all elements of landscape in the garden are to express the designer's ideal sentiment with main creation technique of the fusion of scene and feeling, and expressing feelings into the nature. On the design, the large to space layout, and the small to flowers and plants, basically are the elements that designers rebuild nature and express feelings. Methods of modern landscape design is also beautiful environment creation, also reflects the worship to nature. The poetic imagery beauty of Chinese garden and idea of beauty of modern landscape theme, also need to be conveyed by these elements, and also need the viewers' understanding to produce the spiritual resonance and feel the poetic imagery beauty in modern landscape.

\section{REFERENCES}

[1] Peng Yigang. The Analysis of Chinese Classical Gardens. Beijing: China Building Industry Press, 1986

[2] Wang Honglan.Chinese Classical Architectural Aesthetics [M].

[3] Yinchuan: Ningxia People's Publishing House, 2006

[4] Yu Kongjian. Landscape: Ecology. Culture. Perception [M]. Beijing Science Press, 2005.10

[5] Zhang Jiaji. The Chinese Garden Art Dictionary .Shanxi:

[6] Shanxi Education Press, 1997 